have been recorded from five species of flatworm. There is also a considerable body of descriptive work on these two ciliates; but the ecology seems to have been neglected. The existence of a pond with a large flatworm population in the grounds of the Memorial Buildings, University College, Bangor, has afforded an opportunity of studying the seasonal population changes in $U$. mitra, and some interesting results are emerging. Two species of flatworm abound here, Polycelis nigra and Dugesia lugubris. Early work suggesting that the epizoite was confined to the former species was confirmed by examining four samples of worms from different parts of the pond. of fifty-three $P$. nigra taken, all carried the ciliate, whereas the twenty-four $D$. lugubris were negative. Host specificity seemed absolute under natural conditions. No similar record has been found, although Peshkowsky ${ }^{1}$ noted that both peritrichs were more abundant on $P$. nigra than on Dugesia torva or $D$. lugubris. So far, $T$. steinii has not been found in this pond, although more than five hundred flatworms have been examined.

The preference for $P$. nigra has been tested experimentally by exposing both species of worm simult. aneously to Urceolaria in watch-glasses. Successful attachments were noted after two days-under experimental conditions Urceolaria rarely lived longer, unattached. In ten tests an average of four out of ten (limits, 1-7) Urceolaria became attached to $P$. nigra. They did not attach to $D$. lugubris, confirming the field preference. In further experiments $D$. lugubris alone was exposed, and in three out of ten tests attachment occurred, the numbers being 2,1 and 3 . In the last case the peritrichs lived at least eleven days. Thus under certain conditions specificity is not absolute, recalling Fulton's work $^{2}$ on the transference of $T$. pediculus from $H y d r a$ to the gills of Amphibia. Results suggest that the basis of field specificity may be the amount of pigment and its distribution-it does not seem to be ecological.

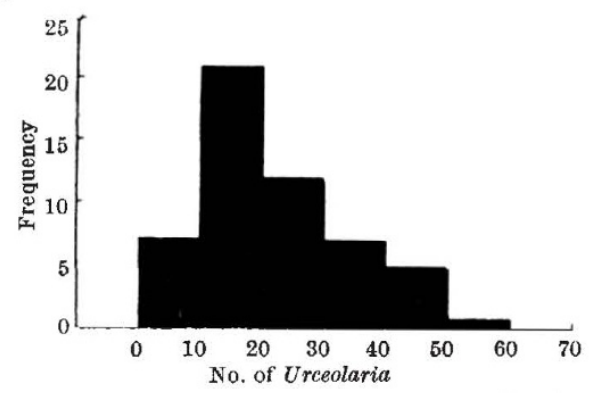

rig. 1. Urceolarian POPULATION OF Polycelis nigra

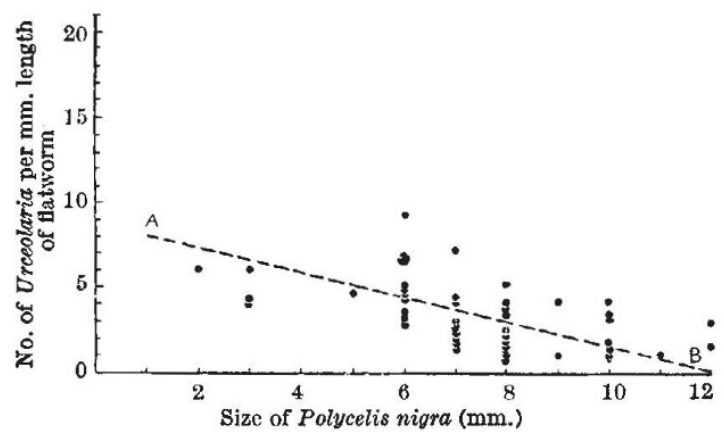

Fig. 2. No. of Urceolaria PER MM. LENGTH ON Polycelis nigra; $A B$ IS THE REGRESSION LINE
Paucity of British records of this association ${ }^{3}$ suggests that it is infrequent, but examination of flatworms from three other habitats in the Bangor district all yielded Urceolarians. Polycelis cornuata carried both species and is a new host record. Not only is the incidence of the epizoite high, but also individual flatworms may carry large populations. Fig. 1 summarizes the data for the College pond; the average number was 22 with limits of 6-55. Arrangement of the data in the form of a trend relating the Urceolarian population to flatworm size shows that the larger specimens do not carry a larger epizoic fauna. It follows (Fig. 2) that the larger flatworms carry a smaller population per unit area. The negative correlation between worm-size and the ciliate population is statistically significant. No explanation of this result, confirmed by later work, is available yet.

It is proposed to study the basis of host specificity, the ecological links between epizoite and host and the factors controlling the size and fluctuations of the peritrich population.

I am indebted to Miss M. Henderson for assistance in the field work and the preparation of this note.

Zoology Department, T. B. ReYNOLDSON

University College of North Wales, Bangor. May 9.

1 Peshkowsky, L., Arckh. russk. protist. Obsheh., 2, 249-279 (1923).

- Fulton, J., Proc. Boston Soc. Nat. Hist., 37, 1-30 (1923).

Whitehead, H., J. Quekett Micr. Cl., 2nd series, 12, 544 (1915).

\section{A Fluorescent Reaction of Tryptophane}

IN studying the colour reactions of tryptophane, described by $\mathrm{J}$. Tillmans and A. Alt ${ }^{1}$, an intense yellow fluorescence under ultra-violet light was observed.

This reaction has been somewhat improved by me for the purpose of fluorescent analysis. It is carried out by adding to $0 \cdot 5-2$ c.c. of the solution of tryptophane in a test-tube a few drops of a dilute solution of formaldehyde (about 4 per cent); the mixture is then shaken, and concentrated sulphuric acid cautiously poured to the bottom. At the contact of the liquid layers a yellow-brown ring appears, which shows intense yellow fluorescence under ultraviolet light. This fluorescence is readily observable with the naked eye in solutions containing $5 \gamma$ per c.c., that is, in a dilution of $1: 200,000$. After shaking, the whole solution shows yellow fluorescence. Solutions containing only the tryptophane fluoresce a bright blue under ultra-violet light.

I have not yet succeeded in isolating the fluorescent colouring matter. It is possibly a 4-carbolin derivative, as a carbolin ring is readily formed by the action of aldehydes upon tryptophan $\theta^{2,3}$.

The colouring is permanent. The intensity of fluorescence remains in a stoppered test-tube unchanged for several months.

Research and Control Institute,

\section{J. V. Kostrr}

United Pharmaceutical Works, and

Institute of Organic Chemistry, Charles University, Prague.

${ }^{1}$ Tillmans, J., and Alt, A., Biochem. Z., 164, 135 (1925).

'Hahn, G., Bärwald, L., Schales, O., and Werner, H., Ann. Chem., 520,107 (1935). s Harvey, D. G., Miller, E. J., and Robson, W., J. Chem. Soc., 153
(1941). 